\title{
LA POESÍA GALLEGA ACTUAL. RETRATO DE FAMILIA
}

\author{
María Xesús Nogueira Pereira \\ Universidade de Santiago de Compostela
}

\section{Introducción ${ }^{1}$}

Como el propio título indica, el objetivo de estas páginas no es otro que ofrecer una panorámica de la poesía gallega de nuestros días y dar noticia de sus principales tendencias, tensiones y nombres.

El público conocedor de trabajos de esta naturaleza es consciente de sus particulares limitaciones, como son la falta de distancia temporal con respecto al objeto de estudio, el reduccionismo que supone toda visión panorámica y la subjetividad de quien escribe, agente, al fin y al cabo, del campo literario que se dispone a explicar.

Asumidos todos estos riesgos, he de enfrentarme a la tarea de deshacer la vaguedad que entraña el término actual y delimitar cronológicamente el período tratado. En este sentido, debo aclarar que, aun habiendo optado por exponer la situación de la poesía gallega en la actualidad, no renuncio a proporcionar información sobre las últimas décadas, fundamental para entender el panorama de hoy.

Finalmente, y con respecto al corpus que voy a estudiar, no creo necesario explicar que por literatura gallega entiendo aquella que utiliza como vehículo esta lengua. Quedan, por lo tanto, fuera del sistema literario gallego escritores que han optado por el cultivo de la literatura en lengua española. Una interpretación errónea de esta cuestión ha generado visiones distorsionadas de la literatura gallega, sobre todo en lecturas llevadas a cabo desde fuera de ella.

1.- Este trabajo se enmarca en el proyecto de investigación Poesía y género: poetas irlandesas y gallegas contemporáneas (1980-2004) (huм2005-04897/FILo), financiado por el Ministerio de Educación y Ciencia). 


\section{LA POESÍA GALLEGA ACTUAL. RETRATO DE FAMILIA}

En las páginas que siguen pretendo pues ofrecer un retrato de familia de la poesía de hoy escrita en lengua gallega, así como ofrecer unas pinceladas acerca de su historia más reciente que permitan entender su evolución hasta el momento actual.

\section{La historia necesaria}

La mencionada imagen del retrato de familia apunta ya hacia una de las conclusiones que se desprenden de una simple observación del elenco de autores productivos, como es la convivencia generacional.

Para comprender mejor esta situación es necesario repasar brevemente la evolución del género poético de la posguerra a la actualidad. Como en el resto del estado español, también en Galicia la historia literaria del siglo XX está articulada por los acontecimientos trágicos de la Guerra Civil y por el régimen instaurado al final de esta. La persecución ideológica y cultural, que tuvo en Galicia una mayor complejidad debido a la cuestión idiomática, abrió un largo período de silencio que se extiende hasta la década de los cincuenta. Durante esta etapa, la producción literaria es anecdótica y una parte importante de las iniciativas se desplazaron al exilio hispanoamericano.

Algunos estudiosos del género se han enfrentado a la tarea de identificar las promociones poéticas coincidentes en este período. La propuesta más citada ha sido sin duda la del profesor (además de poeta y narrador) Xosé Luis Méndez. Ferrín, quien distingue tres generaciones:

1. La Generación de 1936, integrada por autores que vivieron la Guerra Civil y los años posteriores: Aquilino Iglesia Alvariño, Álvaro Cunqueiro, Celso Emilio Ferreiro (iniciador de la corriente social realista) y Xosé María Díaz Castro.

2. La Promoción de Enlace, formada (como su propio nombre indica, sin mucha cohesión) por autores que habían iniciado su escritura en lengua castellana. Entre sus miembros figuran las escritoras Luz Pozo Garza y María do Carmen Kruckenberg.

3. La Generación de las Fiestas Minervales ${ }^{2}$. Para Méndez. Ferrín, se trata de la primera generación estrictamente de posguerra. El autor identifica además en sus integrantes algunos rasgos comunes, como el monolingüismo y la participación en empresas colectivas. Forman parte de esta promoción, entre otros, Manuel María, Uxío Novoneyra, Xohana Torres, Manuel Álvarez Tornciro, Bernardino Graña, Antón Avilés de Taramancos, Salvador García-Bodaño y Xosé Alexandre Cribeiro (Méndez Ferrín, 1984, 1990).

Estudiosos posteriores siguieron, en ocasiones con matices, esta propuesta de periodización (Tarrío 1994, Vilavedra 1999). Algunos se apartaron del enfoque generacional y prefirieron señalar tendencias dentro de este magma poético (Raña 1996). En cualquier caso, la presentación de Méndez Ferrín permite apreciar la complejidad de un período protagonizado por una serie de voces que han ido evolucionando de manera desigual con el paso de los años. En este sentido, es importante indicar que muchos de estos escritores han seguido publicando libros hasta el fin del milenio y algunos continúan haciéndolo en la actualidad. Así ocurre con varios de los integrantes de la Generación de las Fiestas Minervales.

Bernardino Graña (1932) publicó, además de su obra completa (Ardentína. Obra poética completa, 1995), dos libros de poesía en la década de los noventa: Himno verde (1992) y Luz de novembro (1997). Recientemente ha presentado también Sen sombra e sen amor (2004).

2.- Las Fiestas Minervais (Fiestas Minervales) fueron certámenes poéticos celebrados en Santiago de Compostela en el siglo XVII y recuperados en el año 1953 por el SEU. Los poetas de esta generación participaron y fueron galardonados en ellas. 


\section{MARÍA XESÚS NOGUEIRA PEREIRA}

Manuel Álvarez Torneiro (1932), poeta tardío y fértil, publicó As voces consagradas (1993), As doazóns do incendio (1993), Rigorosamente humano (1995), Habitante único (1997), Luz de facer memoria (1999), Campo segado (2001), Epicentro (2003) y Setembro Stradivarius (2004). En su haber figuran además algunos de los premios literarios más importantes de la poesía actual, como el González Garcés (en tres ediciones) o el Esquío. Su testimonio ilustra la evolución personal de algunos miembros del grupo:

Pertenzo, como xa queda dito, á Xeración das Festas Minervais, que rachou con certa tradición literaria galega no que se refire ás solucións estilísticas. No seu momento marcounos a expresión política e social dunha posguerra que perdemos día a día e ó longo de moitos anos. Co tempo e os novos aires que foron entrando no país, cambiaron certos puntos de vista (Casas, ed. 2003: 472) ${ }^{3}$.

Salvador García-Bodaño (1935) ha reunido poemas dispersos en su Obra poética (1993) y continúa su labor productiva en revistas de poesía.

Por otra parte, a pesar de su desaparición, Manuel María (1929-2004), Uxío Novoneyra (1930-1999) y Antón Avilés de Taramancos (1935-1992) siguen siendo una referencia hoy en día para muchos escritores y forman parte indiscutible del canon. El primero de ellos es considerado una figura polifacética imprescindible en la cultura gallega. Además de su Obra poética completa (2001), publicó Compendio de orballos e incertezas (1991) y A primavera de Venus (1993). Uxío Novoneyra llevó a cabo una intensa actividad literaria en la década de los noventa con la publicación de Tempo de elexía (1991), Poemas da doada certeza (1994) y otros textos dispersos. Por su parte, Avilés de Taramancos es una figura singular que después de haber publicado dos libros de poemas en los años cincuenta y emigrado posteriormente a Colombia, se integró a su regreso en la vida literaria gallega. En la década de los noventa publicó Última fuxida a Harar (Derrotas e singraduras) (1992), verdadero testamento poético del escritor.

Una mención aparte merece Xohana Torres (1931), quien en 1992 publica Tempo de ría, con el que se sitúa en la órbita de las escritoras que predenden llevar a cabo una relectura de la tradición y conquistar un espacio en el territorio literario. Por esta razón, su obra ha sido reiteradamente seguida y homenajeada por las escritoras más jóvenes:

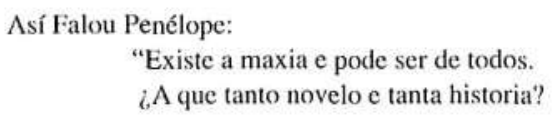

EU TAMÉN NAVEGAR 4 .

La Generación de las Fiestas Minervales es también la promoción poética del propio Xosé Luis Méndez Ferrín (1938), otra de las referencias indiscutibles para escritores de edades dispares. Con pólvora e magnolias (1976) ha sido considerado uno de los libros que marcaron un cambio de rumbo en la poesía gallega. Posteriormente, el autor publicó Poesía enteira de Heriberto Bens (1980), de naturaleza social, aunque alejado de la estética social realista, O fin dun canto (1982), Estirpe (1994) y Era na selva de Esm (2004), colectánea de textos escritos en diferentes etapas de su vida. Méndez. Ferrín ocupa un lugar central e indiscutible en la poesía gallega contemporánea.

3.- «Pertenezco, como ya queda dicho, a la Generación de las Fïestas Minervales, que rompió con cierta tradición literaria gallega en lo que se refiere a las soluciones estilísticas. En su momento nos marcó la expresión política y social de una posguerra que perdimos día a día a lo largo de muchos años. Con el tiempo y los nuevos aires que han ido entrando en el país, cambiaron ciertos puntos de vista». Las traducciones son mías.

4.- «Así habló Penélope: // "Existe la magia y puede ser de todos. / ¿Para qué tanto ovillo y tanta historia?" // YO TAMBIÉN NAVEGAR». Véase González 2005. 


\section{LA POESÍA GALLEGA ACTUAL. RETRATO DE FAMILIA}

También las escritoras de la Promoción de Ennlace citadas más arriba continúan ejerciendo en la actualidad un intenso oficio poético. María do Carme Kruckenberg (1926) ha publicado en los últimos años Poemas sen resposta (1999), Obra poética casi completa (2000), Lembranzas da beleza triste (2003) y Luz para un novo amencer (2004). Luz Pozo Garza ha tenido igualmente una presencia intensa y notoria en la vida literaria gallega. En los últimos años ha publicado Prometo a flor de Loto (1992), Vida secreta de Rosalía (1996), As arpas de Iwerdoon (2005), además de su obra completa Memoria solar (2004).

Ninguno de los poetas de la Generación de 1936 ha sobrevivido hasta época actual. Sin embargo, en algunos casos, su obra ha estado muy presente en las promociones posteriores. Es el caso de Álvaro Cunqueiro (1911-1981), que influyó notablemente en los poctas que comenzaron a escribir en la década de los ochenta con su último poemario, Herba aquí e acolá (1980). Algunas voces críticas han llegado a ver en este libro una pieza fundamental en la transformación estética ocurrida por aquellos años.

Un caso aparte lo constituye Celso Emilio Ferreiro (1912-1979), iniciador de la poesía social ${ }^{5}$ en Galicia. El título de su libro Longa noite de pedra (1962) ha sido reiteradamente utilizado para designar los oscuros años del franquismo.

La corriente social dominó la poesía gallega durante la década de los sesenta y conoció una notable difusión gracias a las versiones musicadas por los cantautores de la Nova Canción Galega, surgida por aquellos años.

La poesía social realista de los últimos años de la década de los 60 y principios de la de los 70 da muestras de su agotamiento tanto temático como formal, según testimonian sus últimos textos. Los tópicos heredados de Celso Emilio y de la poesía social en lengua española delatan su carácter epigonal. En 1973 María Victoria Moreno Márquez cumplió el encargo editorial de elaborar una antología de Los novísimos de la literatura gallega, siguiendo el modelo de José María Castellet. Tampoco en este caso la colectánea presentaba ninguna estética novedosa, sino a los epígonos de una estética que en aquel momento estaba paralizando la creatividad poética. La fecha ha sido utilizada, de manera simbólica, para delimitar el fin de la poesía social en Galicia.

\section{Transición poética y cambio}

El nuevo marco político que se dibujó con el final de la dictadura favoreció, como era de esperar, la difusión de la literatura gallega y creó un ilusionante horizonte de expectativas en el terreno sociocultural, en el que se había marcado como objetivo urgente la normalización de los usos lingüísticos.

Fue también por estas fechas cuando se inició un proceso renovador de la poesía gallega que desde hacía algún ticmpo parecía necesario. Los signos de este proceso se advirtieron (no sin discusión) en tres poemarios publicados en el emblemático año de 1976: el mencionado Con pólvora e magnolias, de Xosé Luis Méndez. Ferrín; Mesteres, de Arcadio López-Casanova (1942); y Seraogna, de Alfonso Pexegueiro (1948).

El primero de ellos armonizaba una estética de cuño culturalista con un discurso social alejado, como ya se ha dicho, de las actitudes y lugares comunes de la poesía social realista. El libro ha alcanzado ya la condición de clásico y con él han dialogado voces poéticas posteriores.

Mesteres es un poemario de estructura salmódica que, aun resultando novedoso en aquel momento, no ha ejercido tanta influencia en la poesía gallega. Por su parte, Seraogna (palíndrome de Angoares, localidad natal del autor) es un libro rupturista e innovador desde el punto de vista formal, que tematiza aun así cuestiones sociales.

5.- Celso Emilio Ferreiro es también autor de una poesía intimista y existencial, que ha sido tardíamente valorada. 


\title{
MARÍA XESÚS NOGUEIRA PEREIRA
}

Algunos estudiosos han encontrado precedentes de esta ruptura en el poema experimental de Uxío Novoneyra "Viet Nam Canto" o en la mencionada Poesía enteira de Heriberto Bens. En los dos casos se trataba de nuevas formulaciones de un discurso de contenidos sociales. Además, han incluído en esta nómina otras obras como Poesía experimental (1978), de Xavier Seoane (1954), Paisaxe de Glasgow (1978), de Vicente Araguas (1950), E direi-vos eu do mister das cobras (1980), de Manuel Vilanova, además del ya citado Herba aquí e acolá (1980), de Álvaro Cunqueiro.

En cualquier caso, la crítica ha percibido un cambio de rumbo necesario en una poesía estancada cuya modernización urgía. La proliferación de actividades culturales, hasta ese momento vigiladas por la censura, permitió una presencia notable de la poesía en la sociedad, a través de su publicación en revistas (numerosas en estos años), concursos y recitales.

En este momento surgieron también grupos poéticos de distinto signo. En algunos casos el objetivo principal era la publicación de los textos de sus autores en un volumen conjunto (Alén, Cravo Fondo, De amor e desamor). Otras veces, sus miembros compartieron un fuerte espíritu grupal. Es el caso del mítico Grupo de Comunicación Poética Rompente, que ejerció sus actividades provocadoras e iconoclastas (recitales, hojas volanderas, performances, espectáculos, etc.) desde 1975.

\section{La poesía de los ochenta}

La labor de modernización de la poesía gallega fue asumida también por una serie de escritores jóvenes que empezaron a publicar sus libros en torno a 1980: Xavier Seoane, Manuel Rivas, Claudio Rodríguez Fer, Manuel Vilanova, Vicente Araguas, Pilar Pallarés, etc.

La afluencia de poemarios llevó a hablar, años después, con euforia de una nueva edad dorada para la lírica gallega. La novedad que estos libros aportaban consistía fundamentalmente en el retorno a temas clásicos, como el amor o el paso del tiempo, la práctica del culturalismo y un cuidado formal que contrastaba con los últimos productos de la estética social dominante en los años anteriores. A este grupo de escritores y escritoras ${ }^{6}$ se los denominó poetas de los ochenta, cuando no generación de los ochenta, marbete menos apropiado por los problemas que el término generación suscita, a no ser que se emplee en un sentido sociológico cultural ${ }^{7}$. La solidez de este grupo se vio reforzada por algunos estudios y antologías aparecidas a partir del primer lustro de la década, entre los que cabe destacar Desde a palabra doce voces. Nova poesía galega (1986), de Luciano Rodríguez Gómez, debido a su función canonizadora ${ }^{8}$.

La crítica ha insistido en la propensión de estos autores al culturalismo, actitud que contrastaba claramente con la temática de la poesía social. En este sentido debemos tener en cuenta la incorporación de referencias procedentes de diversos ámbitos de la cultura y de las artes. Los versos que siguen constituyen un buen cjemplo de esta afirmación:

\footnotetext{
Aracné é Helena tecendo o que por ela

Penélope destece mentras agarda o fin.

Aracné é Lesbia amando obscenamente

a Catulo o poeta. Aracné é Beatriz.

camiñando con Dante ou Laura namorando

a Petrarca nesa arca segreda
}

\begin{abstract}
6.- La incorporación masiva de la mujer a la poesía ha sido más tardía. Aún así, a lo largo de esta década publican sus primeros libros poéticos Pilar Pallarés, Xela Arias, Ana Romaní, Pilar Cibreiro, Marica Campos y Ánxeles Penas. 7.- Esta aplicación fue sugerida por Casas (2003).

8.- Henrique Monteagudo (1985) y Claudio Rodríguez Fer (1986) publicaron también artículos pioneros sobre el nuevo panorama poético.
\end{abstract}




\title{
LA POESÍA GALLEGA ACTUAL. RETRATO DE FAMILIA
}

\author{
que é o poema en que a Lisi \\ fixo Quevedo eterna na pocira do tempo. \\ Aracné é Diótima desvelando a Platón \\ e Cósima celebrando o ritual de Wagner: \\ aquela Margarida que rexuvenece a Goethe?
}

\section{Claudio Rodríguez Fer, Historia da hía (1986)}

La apertura temática, actitud compartida por estos escritores, permitió superar la pobreza en la que se había sumido el discurso poético en los años anteriores. De ella son buena muestra algunos títulos: "Ingrid Bergman" (Xesús López Valcárcel, Tránsito, 1984), "Tirteo oponse aos estandartes do outono" (Ramiro Fonte, As cidades da nada, 1985), Entre água e fogo (Cantos da terra posuída) (Miguel Anxo Fernán Vello, 1987), "L'eclair" (Manuel Forcadela, O regreso das ninfas, 1985), etc.

Con todo, en la producción de estos escritores se percibe, al mismo tiempo que un constante ejercicio de culturalismo y de intertextualidad, una recuperación del repertorio temático más clásico. Obsérvense, en este sentido, títulos como "Cando Hades nos xulgue" (Román Raña, Nas areias doutro mar, 1984), "Os tristes" (Eusebio Lorenzo Balcirón, O corpo e as sombras, 1985), Arquitecturas de cinza (Xosé María Álvarez. Cáccamo, 1985) o A morte presentida (Eusebio Lorenzo Baleirón).

El otro rasgo que ha sido reiteradamente observado en estos escritores es el cuidado formal de sus composiciones, tanto desde el punto de vista métrico (donde hay una tendencia al verso clásico) como desde el lingüístico. En este sentido, la progresiva implantación de la enseñanza de la lengua gallega en los distintos niveles educativos y el impulso de los estudios lingǘ́sticos no han sido ajenos a esta cuestión. Tanto la claboración de un código poético culto y notablemente enriquecido en lo que se refiere al léxico, como el cuidado métrico y compositivo en general, contrastan con las actitudes de los últimos cultivadores del discurso social realista.

Sin cmbargo, a la hora de ofrecer una panorámica de la poesía de estos años es necesario hacer frente una simplificación derivada de la reducción, por parte de algunos sectores de la crítica, de la poesía de los ochenta a una estética culturalista y de exquisita expresión formal. Aún siendo esta la tendencia dominante, su valoración fue tan grande que llegó a eclipsar otras tendencias que han convivido igualmente con ella a lo largo de todos estos años. En realidad, en la producción poética de los años ochenta, han concurrido las siguientes tendencias:

1. La poesía culturalista, cultivada por Xosé María Álvarez. Cáccamo (1950), Manuel Forcadela (1958), Román Raña (1960), Paulino Vázquez (1962), Eusebio Lorenzo Baleirón (1962-1986), Ramiro Fonte (1957), y Miguel Anxo Fernán Vello (1958), entre otros. Como ya se dijo, ha sido la estética dominante en la época. Algunos de estos poetas han evolucionado hacia una poesía más comunicativa en sus poemarios posteriores. Salvo en el caso de Eusebio Lorenzo Baleirón, fallecido prematuramente en 1986, todos ellos han continuado productivos. Algunos de ellos (Román Raña, Fernán Vello) han sido recientemente galardonados en prestigiosos premios de poesía.

2. La poesía de la experiencia, escrita en un lenguaje más directo. Se trata de un discurso natural, que aborda cuestiones cotidianas e incluso esboza una temática de naturaleza social. Siguieron esta tendencia Antón L. Dobao (1963), que acaba de publicar Materia

9.- «Aracné es Helena tejiendo lo que por ella / Penélope desteje mientras espera el final. / Aracné es Lesbia amando obscenamente / a Catulo el poeta. Aracné es Beatriz / caminando con Dante o Laura enamorando / a Petrarca en esa arca secreta / que es el poema en que a Lisi / hizo Quevedo eterna en la polvareda del tiempo. / Aracné es Diótima desvelando a Platón / y Cósima celebrando el ritual de Wagner: / aquella Margarita que rejuvenece a Goethe». 


\section{MARÍA XESÚS NOGUEIRA PEREIRA}

(2005) y Manuel Rivas (1957). A este último pertenece el siguiente poema, ilustrativo de este discurso:

\section{VIUDAS DOS VIVOS}

Elas escrevian cartas
con abrentes de mel e biscoito
e chegaban postais con vermellos tranvías,
xardíns de acuarela,
cadelos de algodón,
c unha parella absurdamente feliz enriba da ponte de Westminster

Balada nas praias do Oeste (1985)

3. La poesía experimental, practicada entre otros por Xavier Seoane (1954) en sus inicios, Manuel Vilanova (1944), Vicente Araguas (1950) y Miguel Sande (1961).

4. La poesía de mujer que, con la excepción de Pilar Pallarés (1957), que publica su primer libro en 1980, comienza a surgir a mediados de la década, con voces como Xela Arias (1962-2003,) Ana Romaní (1962) y Marica Campo (1948).

Además de estas tendencias debemos tener en cuenta la trayectoria de voces singulares, como Claudio Rodríguez Fer (1956), Luis González Tosar (1952), Cesáreo Sánchez Iglesias (1951) o Miguel Anxo Murado (1965).

\section{La poesía de los noventa}

Aun asumiendo el carácter artificial de una periodización basada en el cómputo de décadas, lo cierto es que la de los noventa dio comienzo con nuevo aluvión de poemarios frescos y novedosos, que superaban un impasse detectado por algunas voces críticas en los últimos años ochenta.

También en este caso se trataba de poetas en su mayoría jóvenes, que irrumpían con algunas propuestas que marcaban, en general, una importante distancia con respecto al discurso dominante en los ochenta. Casi todas ellas tenían su base en una concepción más comunicativa de la poesía y en una huída de los hábitos más clásicos y barroquizantes. En este sentido, se observa una propensión a formas de menor extensión, concebidas al margen de los esquemas de la métrica tradicional" ${ }^{11}$.

El culturalismo deja de ser una práctica habitual en estos escritores, que ensancha sus referentes a campos no necesariamente pertenecientes a productos canonizados. Otras veces queda relegado al registro irónico, como ocurre en algunos escritores especialmente empeñados en revisar y superar modelos anteriores. Una buena muestra de esta actitud es el único libro publicado por el extinto e iconoclasta grupo Ronseltz, que había sido fundado en la década anterior (lo que prueba, por otra parte, la pluralidad antes mencionada). Se trata de Unicornio de cenorias que cabalgas os sábados, volumen póstumo aparecido en 1994:

Da imposibilidade de construir

un discurso de vangarda

10.- «VIUDAS DE LOS VIVOS // Ellas escribían cartas / con amaneceres de miel y bizcocho / y llegaban postales con rojos tranvías, / jardines de acuarcla, / perros de algodón, / y una pareja absurdamente feliz sobre cl puente de Westminstern.

11.- Como se verá, hay sin embargo algunos escritores caracterizados precisamente por el cultivo de formas clásicas. 


\title{
LA POESÍA GALLEGA ACTUAL. RETRATO DE FAMILIA
}

\author{
por que mi ideología nacionalista \\ me lo impide \\ 1 \\ Diálogo de fío telefónico \\ BIBL.: Wayne C. BOOTH, The rethoric of fiction \\ -Está Panero? \\ -Quen o chama? \\ -Un compañeiro vangardista. \\ -Un momentito. \\ FIN $^{12}$
}

El texto ironiza sobre un debate central en la historia del sistema literario gallego, como es la dificultad de armonizar el espíritu de vanguardia con el compromiso nacionalista en los albores del siglo XX. Este ejercicio culturalista de tintes desenfadados, cuando no paródicos, se percibe también en otros escritores, como María do Cebreiro (Nós, as inadaptadas ${ }^{13}, 2002$ ), Manuel Outeiriño ("Certa extensión (agraria?)", Depósito de espantos, 1994), entre otros.

Dado su carácter abierto, cualquier intento de sistematización de esta producción podría resultar impreciso. Me limitaré en este caso a identificar las principales tendencias poéticas que se han registrado en estos años. Creo aún así necesario dejar claro que se trata de un boceto sobre el que habrá que volver dentro de algún tiempo. Por otro lado, tampoco en esta ocasión pretendo ofrecer una nómina exhaustiva, sino unos apuntes que puedan ayudar a comprender el panorama poético actual.

1. La poesía de la cotidianeidad, que se ha valido de una expresión natural y sencilla, alejada en general de artificios retóricos y juegos interetextuales, para buscar una comunicación más directa. Esta tendecia discursiva, seguida por Rafa Villar (1968), Helena de Carlos (1964) o Marta Dacosta (1966), ha generado textos desnudos y transparentes que a menudo recuperaban los grandes temas de la poesía universal:

a casa
nunca tivo chave
gardouna a maré
entre os seus
devalos
unha chave
sería unha rede
intacta ${ }^{14}$

Rafa Villar, casa ou sombra (1997)

2. La poesía de lo coloquial. Se trata de un paso más en este proceso de distanciamiento de una poesía ebúrnea. Se trata de un discurso poético que aborda, con un tono en general desenfadado, temas contemporáneos enmarcados a menudo en escenarios urbanos. Es este

12.- «De la imposibilidad de construir / un discurso de vanguardia / porque mi ideología nacionalista / me lo impide. // 1. // Diálogo de hilo telefónico // BIBL.: Wayne C. BOOTH, The rethoric of fiction // - ¿.istá Panero? / ¿Quién le llama? / -Un compañero vanguardista. / -Un momentito. // FIN".

13.- Nós os inadaptados (1920) es un ensayo de Vicente Risco en el que este explica su evolución ideológica desde las actitudes escapistas y descomprometidas de su juventud hasta el nacionalismo gallego.

14.- «la casa / nunca tuvo llave // la ha guardado la marea / entre sus / reflujos // una llave / sería una red / intacta». 


\section{MARÍA XESÚS NOGUEIRA PEREIRA}

un camino seguido por Fran Alonso (1963), Carlos Negro (1970) en su poemario Far west o Kiko Neves, a quien pertencen estos versos:

Venres, 23 (mañán)

Levo catro días sen saír.

Non chama.

Non teño o poema.

Nin pilas para o mando

do televisor.

Teño que erguerme a cada intre.

Dóeme a cabeza.

Aínda hai cervexa no

frigorífico. E olivas. E tabaco.

E máis unha desorde xeral

da festa que fixen onte

á noite.

Sen ela ${ }^{15}$.

Un poema de amor (1998)

3. Un discurso lírico-narrativo que recrea a menudo simbologías personales. Esto genera en ocasiones poemarios concebidos como macrotextos. Así ocurre en As laranxas de alí babá (1998) o en los poemarios de Estevo Creus (1971):
A min e non a ti
mordeume de neno unha balea
e no espiral de A.D.N.
mesturáronseme a dolor con tres pasos e tres golpes:
as chemineas enchéronse dos bechos máis pequenos
a cola do alacrán habitoume polos brazos
c a memoria
a memoria
a memoria é un animal
con solitaria ${ }^{16}$

Poemas da cidade oculta (1996)

4. El discurso social, profundamente revisado en esta década, ha encontrado caminos nuevos que van del realismo (Fran Alonso), al discurso político (Igor Lugrís, 1971), pasando por un complejo ejercicio de deconstrucción discursiva practicado por Chus Pato (1955), quien revienta los discursos asociados al poder y denuncia las contradicciones del propio lenguaje:

15.- «Viernes, 23 (mañana) // Llevo cuatro días sin salir. / No llama. / No tengo el poema. / Ni pilas para el mando / del televisor. / Tengo que levantarme a cada momento. / Me duele la cabeza. // Aún hay cerveza en el / frigorífico. Y aceitunas. Y tabaco. // Y un desorden general / de la fiesta que hice ayer/por la noche. // Sin ella».

16.- «A mí y no a tí/ me mordió de niño una ballena / y en la espiral de A.D.N./ se mezclaron el dolor con tres pasos y tres golpes: / las chimeneas se llenaron de los bichos más pequeños / la cola del alacrán me habitó por los brazos // y la memoria // la memoria // la memoria es un animal / con solitaria". 


\title{
LA POESÍA GALLEGA ACTUAL. RETRATO DE FAMILIA
}

\author{
A miña lingua nativa é o fascismo \\ a imposibilidade do fascismo para dicir os nomes do real. \\ Perturbación \\ Orixe $^{17}$
}

\section{Fascinio (1995)}

5. La poesía experimental que, sin ser tampoco en esta década la tendencia dominante, ha seguido viva gracias a las iniciativas de Celso Fernández Sanmartín (1969), Carlos Solla (1971), Carlos Santiago o la Corporación Semiótica Gallega. La recuperación de la experimentación gráfica ha visto enriquecida por las nuevas tecnologías. En ocasiones se ha cargado de ironía y de contenido social; otras ha derivado hacia la poesía visual. $\mathrm{He}$ aquí algunos ejemplos:

busca-palabra

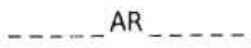

\section{$X X X V I$}

\section{Auto de terminación}

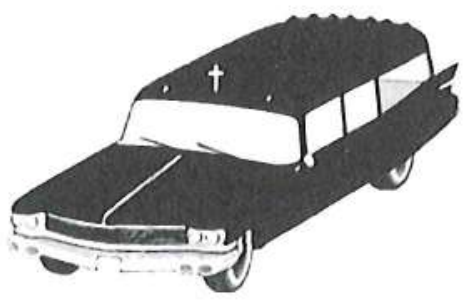

\section{Feiras e fesias}

Carlos Solla, Cerdedo in the Voyager I (2004)

17.- «Mi lengua nativa es el fascismo // la imposibilidad del fascismo para decir los nombres de lo real. // Perturbación // Origen». 


\section{MARÍA XESÚS NOGUEIRA PEREIRA}

Las páginas web y los blogs se han convertido en un espacio adecuado para albergar estas prácticas y su proliferación ha supuesto, también en la literatura gallega, un cambio sustancial en la difusión de la poesía.

6. La escritura femenina, cuya explosión ha sido el gran fenómeno de la década. A las poetas que habían iniciado su obra en la década anterior (Pilar Pallarés, Luisa Castro, Xela Arias o Ana Romaní) se unieron una serie de voces especialmente empeñadas en desarrollar una escritura de género. Se trata de Lupe Gómez (1972), Yolanda Castaño, María Lado (1979), Emma Couceiro (1977), María do Cebreiro (1976), Olga Novo (1975), Emma Pedreira (1978), Cristal Méndez (1964) y Estíbaliz Espinosa (1974), entre otras.

Entre las estrategias que han seguido estas escritoras en la elaboración de sus poéticas destacan el tratamiento del erotismo, la apropiación del lenguaje androcéntrico y la poetización de la encrucijada mujer-nación ${ }^{18}$ :

ENFOQUE TEÓRICO
A muller é
un cristal
atravesado por
unha patria ${ }^{19}$.

Resulta igualmente frecuente la reescritura de representaciones femeninas, preferentemente mitológicas.

7. La poesía que establece un diálogo intertextual con discursos canonizados (filosóficos, literarios o ideológicos.), desde una actitud crítica y desestabilizadora que echa mano a menudo de la ironía. Se trata de una propuesta igualmente rupturista y la mayoría de las veces arriesgada en la que se han visto actitudes propias de la posmodernidad. Además del mencionado colectivo Ronseltz (creador de un discurso rebelde y contracultural), es posible situar en esta línea, entre otros, a Xabier Cordal (1965), María do Cebreiro (1976), Chus Pato y Manuel Outeiriño (1962). A este último pertenece la siguiente muestra:

\section{PRIMUS INTER PAROCHIALES}

Un é unha parroquia inmensa

e pode gobernarse con pastorais

coma as de Alberto Caciro ${ }^{20}$.

Manuel Outeiriño, $\hat{E}(2005)$

Estos escritores demandan un modelo de lector competente, capaz de interpretar unas claves poéticas que se alejan casi siempre de valores comunmente asumidos. Por otro lado, además de demoler discursos canonizados, vulneran en ocasiones el propio código, violentando la sintaxis y disolviendo las fronteras entre los géneros tradicionales. El caso más extremo es probablemente el de Chus Pato, autora que ha consolidado en los últimos años una estética personalísima caracterizada por la destrucción del lenguaje:

interromper ao lector. Seguido

INTERROMPELO

18.- La obra de estas escritoras ha sido seguida y estudiada por Helena González (2005), quien se ha ocupado además de poner de manifiesto esta contradicción a la que se refiere como oxímoron identitario.

19.- «ENFOQUE TEÓRICO // La mujer es / un cristal / atravesado por / una patria». El verso ha sido reiteradamente citado por Helena González en sus estudios (vid. supra).

20.- «Uno es / una parroquia inmensa / y puede gobernarse con pastorales / como las de Alberto Caeiro». 


\section{LA POESÍA GALLEGA ACTUAL. RETRATO DE FAMILIA}

METÁFORA: nun sentido anterior á revolución Lf́RICA moderna (substituír finalmente unha linguaxe "degradada", por outra pretendidamente UNIVERSAL)

corpo-METÁFORA- ligado a un anterior MODO DE PRODUCCIÓN

AGRARIO, que precisa anular toda diferencia

nas súas PROPOSICIÓNS poéticas

a METÁFORA son os campos de CEREAL

O RAPTO DE PERSÉFONA

O DESCENSO AOS INFERNOS

A VIOLAACIÓN

O MATRICIDIO

METÁFORA: monarquía ${ }^{21}$

Chus Pato, m-Talá (2000)

8. El clasicismo, también revisado y cultivado por Miro Villar, Martín Veiga, Modesto Fraga o Xosé Manuel Vélez. Tal vez sea el primero de ellos el más representativo, al diferenciar una praxis militante en su vida pública, claramente comprometida con su país, con el cultivo de una poesía expresada en metros clásicos, actualizados desde el punto de vista temática:

Cos zapatos mollados percorrín Compostela na procura da pedra que miman os teus dedos, por vellas fendeduras escoitei rosmar credos encubertos por fiestras pechas con tarabela.

Os pasos postergaron o eco da cantarela baixando polos viños entre cantos máis ledos mesturados co aroma de ribeiros acedos, de onde fuxín lixeiro por non ter nin cadela.

No Toural un concerto de banda do concello fixo que o desconcerto propio se vise espello que os pés aterecidos desexaban quentura,

vin que espreitantes rostros pelexaban comigo xulgándome de parvo por non ficar ao abrigo. Ningunha chuvia molla como estar na amargura ${ }^{22}$.

Miro Villar, Ausencias pretéritas (1992)

21.- «interrumpir al lector. Seguido. // INTERRUMPIRLO. // METÁFORA: en un sentido anterior a la revolución LíRICA moderna / (sustituir finalmente un lenguaje "degradado", por otro / pretendidamente UNIVERSAL) //cuerpo -METÁFORA - ligado a un anterior MODO DE PRODUCCIÓN / AGRARIO, que necesita anular toda diferencia / en sus PROPOSICIONES POÉTICAS // la METÁFORA son los campos de CEREAL / EL RAPTO DE PERSÉFONA/ EL DESCENSO A LOS INFIERNOS / LA VIOLACIÓN / EL MATRICIDIO // METÁFORA: monarquía».

22.- «Con los zapatos mojados recorrí Compostela / a la búsqueda de la piedra que miman tus dedos, / por viejas hendiduras escuché murmurar credos / encubiertos por ventanas cerradas con tarabillas. // Los pasos postergaron el eco del cántico / bajando por los vinos entre cantos más alegres / mezclados con el aroma de ribeiros ácidos / de donde huí ligero por no tener ni un duro. // En el Toural un concierto de banda del Ayuntamiento / hizo que el desconcierto propio se viese espejo / que los pies ateridos deseaban calor, // vi que expectantes rostros se peleaan conmigo / juzgándome de tonto por no quedar al abrigo. / Ninguna lluvia moja como estar en la amargura». 


\section{MARÍA XESÚS NOGUEIRA PEREIRA}

Las nuevas actitudes de estos poetas no se reflejan únicamente en sus productos, sino también en sus comportamientos públicos. Es importante tener en cuenta el esfuerzo que llevaron a cabo para conseguir no sólo visibilidad sino también protagonismo en un espacio literario ocupado mayoritariamente por sus padres y abuelos. Esta presencia fue posible, en gran medida, gracias a la búsqueda de alternativas para la publicación, desde editoras con espíritu cooperativista enfocadas a autores noveles (Letras de Cal), hasta ediciones de autor (numerosas en el primer lustro de la década), revistas y fanzines o páginas web. Igualmente importantes fueron otros intentos de difundir públicamente la poesía, como los numerosos recitales (a menudo en lugares de ocio), las performances y espectáculos diversos.

En general, el activismo y la militancia culturales caracterizaron el comportamiento de estos escritores que dinamizaron considerablemente el sistema literario a lo largo de la década de los noventa.

\section{Conclusión}

$\mathrm{Si}$, como antes apuntaba, la historia de la poesía gallega más reciente parece contarse por décadas, en los años transcurridos de esta primera del nuevo milenio no se han producido por ahora tensiones ni rupturas importantes y, con la cautela con la que conviene hacer estas afirmaciones, parece que estamos asistiendo a una prolongación de la ctapa anterior.

Autores de promociones anteriores siguen compartiendo espacios públicos y en ocasiones incluso escenarios con los más jóvenes, algunos de los cuales aún no han publicado su primer libro. Ejemplos de esta realidad los encontramos no sólo en los catálogos editoriales sino también en los índices de las revistas y en los programas de algunos recitales o festivales de poesía. La última edición del Festival de Poesía do Condado, en cuyo programa figuraban, entre otros Luz Pozo, María do Carme Kruckenberg, Bernardino Graña, Afonso Pexegueiro, Antón Lopo o María Comesaña, es un claro ejemplo. También lo son los índices de algunos libros colectivos como Xuro que nunca volverei pasar fame. Poesía escarlata, del colectivo Redes Escarlata ${ }^{23} \mathrm{o}$ aquellos publicados en solidaridad con la catástrofe del Prestige (Negra sombra. Intervención poética contra a marea negra o Sempre mar: Cultura contra a burla negra).

El sistema literario actual concede una notable importancia al género poético. Así lo demuestra el entramado editorial, que cuenta con colecciones de poesía en los catálogos de las editoriales más importantes (Edicións Xerais de Galicia y Editorial Galaxia, esta última con la renovada colección Dombate); editoras practicamente especializadas en poesía, que constituyen un referente desde su fundación (Espiral Maior); otras de menor entidad aunque de interesantes fondos en lo que a poesía se refiere (Positivas, TresCtres, Bahia, Toxosoutos, Tris Tram, Frevenza, Francka Editora, Danú, Difusora de Letras, Artes e Ideas, Amastra-N-Gallar, Hipocampo Amigo, etc.); ediciones institucionales, públicas o privadas (Tambo, Diputación de A Coruña o la colección Esquío, de la Sociedad de Cultura Valle-Inclán); ediciones de autor, revistas y páginas web que abren su espacio a la creación y a la crítica, así como numerosos blogs, fenómeno reciente que canaliza también la práctica poética.

Con este telón de fondo, la poesía gallega actual bien podría representarse como un retrato de familia en el que coinciden:

1. La memoria de los ausentes (Uxío Novoneyra, Avilés de Taramancos y Manuel María, fundamentalmente).

23.- Se trata de un grupo de intervención en cuyas filas militan, entre otros, Xosé Luis Méndez Ferrín y Darío Xohán Cabana, al lado de Chus Pato, Xavier Cordal, Antón L. Dobao y otros autores jovencísimos. 


\section{LA POESÍA GALLEGA ACTUAL. RETRATO DE FAMILIA}

2. Las predecesoras Luz Pozo Garza, María do Carme Kruckenberg.

3. Bernardino Graña, Xohana Torres y Xoxé Luis Méndez Ferrín, unidos por distintos lazos de familia.

4. Los poetas de los ochenta.

5. Los poetas de los noventa.

6. Los escritores a contracorriente, dificílmente ubicables en cualquier clasificación.

Esta configuración da como resultado un sistema complejo y de gran riqueza, definido por herencias, afinidades y lazos diversos. La reflexión de Luz. Pozo Garza sobre csta cuestión muestra su conocimiento de la literatura gallega y, por lo tanto, su triple condición de autora, lectora y estudiosa:

O panorama actual da poesía galega é vasto e complexo. Conviven autores pertencentes a xeracións moi recuadas en activo.

[...] En moi superficial conclusión, [...] no panorama da poesía actual galega conviven múltiples voces en diálogo. Entre as tendencias afíns percíbese unha acción osmótica que, por momentos, tende a homoxeneizar sectores e a colorear preferencias e adeptos. Sensualidade e sexualidade son temas xa consagrados en todos os ámbitos. Apréciase un exultante predominio das novas xeracións, superactivas, in crescendo (Casas, ed., 2003: 109-110) ${ }^{24}$.

\section{REFERENCIAS BIBLIOGRÁFICAS}

Casas, Arturo, ed. (2003): Antoloxía consultada da poesía galega 1976-2000. Lugo: Tris Tram.

González Fernández, Helena (2005): Elas e o paraugas totalizador: Escritoras, xénero e nación. Vigo: Edicións Xerais de Galicia.

Méndez. Ferrín, Xosé Luis (1984): De Pondal a Novoneyra. Poesía galega posterior á guerra civil. Vigo: Edicións Xerais de Galicia. 2." ed. 1990.

Monteagudo, Henrique (1985): “Dez anos de poesía galega 1975-1985”, Grial 89, pp. 268-279.

Raña, Román (1996): A noite nas palabras. Unha aproximación á poesía galega de posguerra. Santiago: Sotelo Blanco.

Rodríguez Fer, Claudio (1986): "Nueva poesía gallega", Cuadernos del Norte, Monografías, n. ${ }^{\circ}$ 3, pp. 106-119.

Rodríguez, Gómez (1986). Desde a palabra doce voces. Nova poesía galega. Barcelona: Sotelo Blanco.

Tarrío Varela, Anxo (1994). Literatura galega. Aportacións a unha historia crítica. Vigo: Edicións Xerais de Galicia.

Vilavedra, Dolores (1999). Historia da literatura galega. Vigo: Galaxia.

\footnotetext{
24.- «El panorama actual de la poesía gallega es vasto y complejo. Conviven autores pertenecientes a generaciones muy reculadas en activo. [...] En muy superficial conclusión, [...] en el panorama de la poesía actual gallega conviven múltiples voces en diálogo. Entre las tendencias afines se percibe una acción osmótica que, por momentos, tiende a homogeneizar sectores y a colorear preferencias y adeptos. Sensualidad y sexualidad son temas ya consagrados en todos los ámbitos. Se aprecia un exultante predominio de las nuevas generaciones, superactivas, in crescendo».
} 